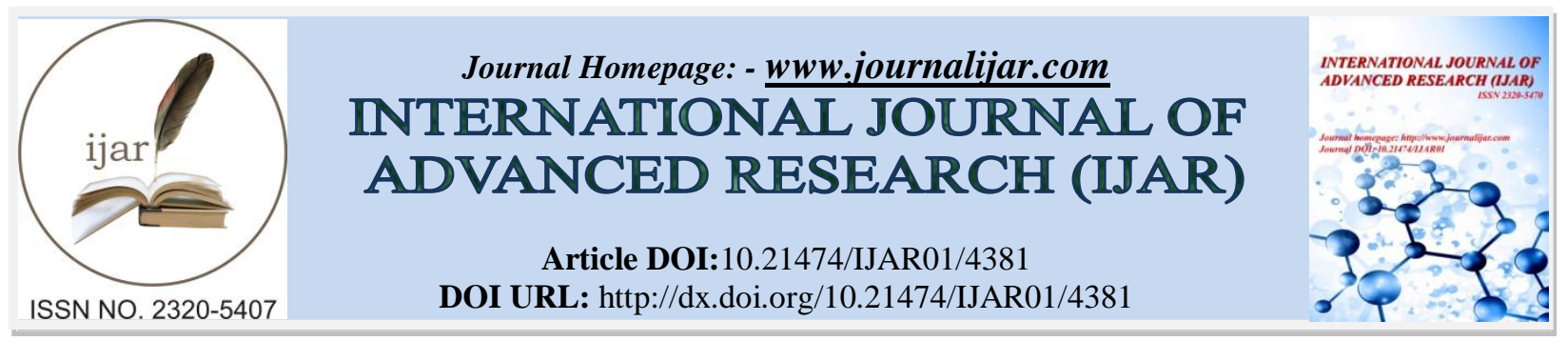

RESEARCH ARTICLE

\title{
ASSESSING THE ACCEPTANCE OF MONETARY OR NON-MONETARY MOTIVATIONAL STRATEGIES IN DEVELOPING ECONOMY LIKE NIGERIA.
}

Okeke Raymond Njelita ${ }^{1}$ and Agu Dennis Eberechi ${ }^{2}$.

1. Department Of Management University Of Nigeria, Enugu.

2. Department of Business Administration and Management Imo State Polytechnic, Umuagwo Campus.

\section{Manuscript Info}

(..........................

Manuscript History

Received: 02 april 2017

Final Accepted: 04 june 2017

Published: june 2017

Key words:-

Motivation, monetary, strategies, nonmonetary, Nigeria

\section{Abstract}

This work is on assessing the reasons for acceptance of monetary motivational strategies or non-monetary strategies in the Ministry of Agriculture and Rural Development of Anambra State of Nigeria. One of the major clogs to workers performance in Nigeria is their unwillingness to exert themselves in their working environment. The objectives of the study are to identify determinants of motivational strategies; to determine non-monetary motivation strategies for organization performance and to highlight the effects of non-monetary motivation strategies on organization performance. The work concluded that, non-monetary motivation strategies have little effect on worker performance in Sub-Saharan Africa; Instability in the polity favours monetary incentive; instability in the organization explains the choice of monetary motivation strategy; individual perception influences choice of motivation strategy; and corruption in the system favours monetary motivation strategy. Therefore the work recommended that non-monetary motivation strategies should be explored as alternative to or use in combination with monetary motivation strategy.

Copy Right, IJAR, 2017,. All rights reserved.

\section{Introduction:-}

Since the beginning of industrial revolution, managers' major preoccupation has been on selecting the best motivation strategy to influence their workers to perform effectively to achieve targeted objectives. They know what motivates workers. The big problem is that they do not know how to use what they know. This is because every environment is characterised by trends and new developments that gradually or speedily produce changes important enough to require a strategic response from organization. It is no longer a question of growth but of survival. Current predictions are that the environment for all organisations will become even more uncertain with every passing year. Markets change and products change with them. Organization tends to update its self and its area of operation and also challenges the assumptions that underline an organization's decision and strategy on motivating workers to higher productivity.

Motivated workers work wonders, their commitment, dedication, creativity and integrity determine whether there is management or mismanagement. They determine long term survival of organization. The starting point of motivation strategy aside from understanding cultural, political, economic etc., of an organization environment, also involve understanding workers internal cognitive processes - what people feel and how they think. This 
understanding helps managers to predict likely behaviour of a worker in a given situation. It indentifies how worker's internal needs affect their subsequent behaviours, drives and needs in order to channel them toward task performance thereby making realisation of organizational objectives possible (Iyer, 2009:32, Mullins, 2007:479).

Management is also responding to the fact that with today's people and today's technology, command and control no longer work best. Their strategy has changed. They seek workers collaboration across the organization. Workers involvement and participation have become standard operating strategy. The need for continuous improvement has triggered numerous work-design changes that are directed towards improving workers and management performance in their industry. The outcome of the industrial revolution was the coming into existence of organizations i.e., coming together of many people in the employment of someone else. Management arose with them and therefore must operate within an organization - that is within a web of human relation (Drucker, 1977:278). The primary target of management at that time was how to improve productivity through efficiency of workers. Workers were seen as one of the factors of production which would be used optimally and discarded when it was no longer yielding expected results. To achieve this, each worker was given a definite task to perform, in a definite manner and motivated to a higher level performance only through monetary incentive. This was with intention of motivating staff so that they work willingly and effectively (Brown,1999:29).

Studies show that there are other factors that motivate workers beside the need for money. These are needs - derived from the nature of the work itself, interest in the job personal growth and development. Others are feeling that they are accepted, that they belong, they can contribute, they can grow, they can achieve their ambitions, can obtain job satisfaction etc., (Belasco, et al., 1981:19). Attention is lately directed towards understanding individuals and their interpersonal relations. A manager's ambition therefore becomes how to influence his workers to do what he wants them to do and continue to do same even when he is not there. This is one of the signs that increasingly a manager is getting it right, success or failure in his organization. A person's motivation will be determined by the comparative strength of these set of needs and expectations and the extent to which they are fulfilled.

Organizations achieve objectives mainly when their employees are willing and able to exert themselves in their work environment (Akpala 1999:26). Organizations manage people and not machinery. People therefore are the most critical of all organisations resources. They determine the success or otherwise of any organization. It involves not only about money, it includes creating an environment in which people enjoy work. It also includes setting a proper organisational structure to maintain free flow of work; recognition of employee performance allowing career progression etc. The success of organization depends on having the right people and motivating them properly. This is because managers achieve intended objectives by working with and through other people. In other words, managers rely on the cooperation of their subordinates. This is because human beings are the only organizational resource that is not restricted by the "law of mechanics"- they can produce more than their input. This is possible only if the motivational strategies actually hit or serve the desired interest of workers.

\section{Objectives Of The Study;-}

1. To identify the determinants of motivation strategies in Nigeria.

2. To determine non-monetary motivation strategies for organization performance.

3. To highlight the effects of non-monetary motivation strategies on organization performance.

\section{Concept Of Motivation Strategy:-}

Motivation strategy is the technique of actuating, arousing, channelling, sustaining and giving workers behaviour purpose and direction toward achieving higher productivity or any other objectives intended by the organization (Akpala,1990:101). It is one of the most patronised areas of management in terms of written, unpublished and published works by researchers. Despite these enormous contributions it still appears not much has been done in this area. This is because motivation is a complex strategy as it concerns dealing with 'why' and 'how' of human behaviour. 'Why'- what makes people do things exposes the uniqueness of individual person. However, there are some things individuals have in common, for example physical, social and growth needs except that the strength of these needs varies from person to person and from time to time within the same person. It also differs from country to country because different countries teach different values and behaviours. Strategists also maintain that needs express themselves in different ways in different cultures. This is not only to achieving objectives, but also to gaining a good work attitude (Mullins, 2007:471, Wild and Wild,2013:372). 
The task of crafting, implementing, and executing motivation strategies is the concern of every manager. That is the 'how' - the strategy that will serve the purpose of management choosing a particular course of motivation in preference to others and continue with the chosen motivation, often over a long period and in the face of difficulties and problems. An organization motivation strategy propels workers to assist their organization in staking out market position, conduct its operations, attract and please customers, compete successfully, and achieve organization objectives. In effect managers are saying that among all the paths and action involved in motivation they could have chosen, they have decided to move in this direction of this particular strategy or combination of strategies (Thompson and Strickland, 2010:3). This underlines the force within individuals by which they attempt to achieve some goals in order to fulfil some needs or expectation. Workers behaviour is determined by how they are motivated. This is critical to the growth and survival of organization. And it is because unless there is action, unless somebody does something, thinking and planning go to waste. Their emotional and practical investment in terms of commitment and dedication to job ensure continued success. These create high level of energy to do things better as well as a restlessness with the statue quo (Dess, Lumpkin and Eisner,2009:387).

Among all the things managers do, nothing affects a company's ultimate success or failure more than how well organisation set its long term strategies of motivation of workers. This involves moves and approaches and implementation of what needs to be done internally to produce good day in day out motivation strategy execution. The idea is to unleash the talents and energies of workers toward realisation of objectives, by letting them try out business ideas and pursuing new strategic initiatives. Doing a good job of managing requires good strategic thinking (Weihrich, Canice, and Koontz, 2010:328). Managers motivate their subordinates by satisfying these drives and desires which induce subordinates to act in a desired manner. Human motives are based on needs, whether consciously or subconsciously felt. Successful executives are driven to achieve beyond expectations - their own and everyone else's. How to meet these needs is what motivation strategy is all about. The 'why' and the 'how' must be at per for subordinates to be motivated i.e., the strategy must meet the expectations of employees and is based on two principal strategies - non-monetary and monetary strategies (Newstrom, 2015:268).

\section{Factors Determining Choice Of Motivation Strategy:- Impact of Globalization:-}

Globalization is the trend towards greater economic, social, cultural, political, and technological interdependence among institutions and economics. It slowly alters cultures and exposes people and products to other cultures, and reshapes the lives of individuals and their perception. We have seen that globalisation impact is not uniform. It affects industries, products and individuals in different ways and to varying degrees. Industries then must create new products, modify promotional campaigns, or adjust their marketing strategies in some other way. People from different countries of Sub Saharan Africa can now interact and relate with the rest of the world through print, electronic and social media. Other cultures and social lives are easily accessed and it influences one's life. Their cultures are being attacked by western cultures through technology. And this is emphasizing free flow of goods, service, ideas and people across national borders. All these influence individual preferences and choice of motivation strategies. The power of globalization can be seen in the inroad Western cultures are making on the cultures of African, Middle East countries, etc. Globalization is changing everything from dressing, shelter, food, individual character and their social interaction etc. All aspect of life is being effect in the Sub Saharan African economy. It is speculated that cultures of peoples of Sub-Saharan African will be seriously affected if care is not taken. Then new realities are transforming the way organisation does business and individual and group behaviour. Most countries in the Middle East have mounted serious campaign to challenge this growing trend (Kumar and Ndihi, 2013:568).

\section{Political Situation:-}

This refers mainly to political situations in different countries most especially in Sub Saharan Africa which often has volatile political environment. The political risk is quite high. Social unrest or open conflict threaten physical facilities, equipment and employee safety. This situation does not encourage invest in the long run. In most cases organisation prefer closing up operations in order to ensure that facilities are not damaged or they prefer transferring their operation to a secure environment thereby extending and aggravating poverty in Sub- Saharan Africa. It is always tense in these areas mainly out of political differences. And because of this tense situation in the polity workers prefer to have all their money in their hands and make use of it as it pleases them. They want to be ready for foreseen and unforeseen occurrences. In Nigeria the event of the $20^{\text {th }}$ and even this $21 \mathrm{ft}$ century have been characterized by some unprecedented uncertainties that created unusual threat as well as opportunities in the socioeconomic, political and business environment. The traditional and conventional tools of business analysis seem to be 
failing both practitioners and policy makers for want of detailed multi-disciplinary approach and total situation study of the Nigeria circumstance. In Nigeria, the business environment has been as erratic and turbulent as the seat of government and governance. Every election period creates tension unlike what is obtainable in the West. This situation does not create environment for proper planning by organisation and its workforce (Imaga and Ewurum, 1998 :42).

\section{Individual Perception/Personality:-}

People differ in their thinking, behaviour, attitudes, preferences and choices. This includes people from different cultures, countries and even people from the same parents. People see things in different ways. This is because individuals have their own unique picture or image of how they see the real world and this is a complex and dynamic process. Perception is the act of all organization behaviour. What interest one person may not actually interest others. Therefore people are not treated alike. An individual choice of non-monetary or monetary motivational strategy is a product of his perception about life. How an individual views a particular situation or invent is personal to him. For example a worker in Nigeria has different perception with a worker in US or any of the Western countries. Sensitivity to individual preferences to motivational strategy is very important. Where organizations embark on applying motivational strategies managers need to be able to value individual differences and be sensitive to contrasting needs. Managers who try to motivate every worker of every nationality through one single strategy have to prepare for disappointment (Mullins,2007:456).

\section{Social Environment:-}

Organization operates in a pluralistic society in which many organized groups represent various interests. Each group has impact on the other. Likewise individuals are also influenced in line with thinking of the group in which they belonged. The human being is a total person influenced by external forces and factors. And they cannot divest themselves of the impact of these forces when it comes to making choices between monetary and none monetary incentives. There is no doubt that the set of core beliefs and value in a society have a high degree of persistence and more often than not influence individual choices. It also shapes and colours more specific attitudes and behaviours found in everyday life. This is because the environment and society in which an individual grew up influences his attitude and preferences. Every social environment influences it citizens in different ways. Therefore one would not expect one that grew up in western countries to have the same attitude or orientation with one who grew up in developing economies of Africa. This is because individual sense of self is shaped by inherited characteristics and by influences in the social environment. This includes family life, the country or community in which he lived has significant part to play in that motivates or interest (Kottler and Keller, 2009:328).

\section{Cultural Environment:-}

Most Sub Saharan African countries are deeply tied to their cultures even at times without any glaring reasons. Culture refers to a way of life of a people and their world view which are encapsulated in their values, beliefs, customs, tradition, language etc. they differ from nation to the other, and from one community to the other. Culture influences the behaviour and attitude of a particular group of people. This is because it shows collective programming of the mind. And it consists of the unwritten social rules that shape individual thoughts and behaviour. In developing economies deep rooted cultural beliefs influence or direct their thinking. Every nationality or nation and community has what they value most in organization in terms of choices of incentives. WShile developing countries have cultural setting different from developed economies. For example in developing country like Nigeria business is conducted on cash and carry bases, while in the developed economies business is mainly on credit. And this cultural orientation reflected on their choice of incentive (Ejiofor and Anagoro, 1982:234).

\section{State of the Economy:-}

The state of the economy influences motivational strategies in an organization. Economy impact on all industries from raw materials to manufacturing of finished goods and services, as well as organization in wholesale, retail, government and non government sectors. Individual choices and preferences are also influenced. People from developing economies of Sub-Saharan Africa are still battling with basic needs- food, clothing and shelter and as such will most probably prefer monetary incentives to meet these challenges. Abraham Maslow refers to these set of needs as physiological, security and social. This situation does not only apply to low level workers, but also senior officials. This is prevalent in developing economies because of uncertainty regarding the nations' future growth. Everybody prefers having his or her money at hand to face rising prices of goods and services that are rising by the day. Therefore, the situation in economic environment is unpredictable. The level of personal disposable income particularly in relation to price level and inflation affects motivation strategies choices. Organization also considers 
the choices of motivational strategy, based on the current revenue, and expedition, prices, savings, and credit availability. This is a situation not likely to be experienced in developed economies.

\section{Level of Education:-}

Education broadens thinking and mind of an individual worker. When people open their minds to receive information and exposure they learn new ways of life or new ways of doing things. It gives individual worker the ability to reason things out before acting. Sub Saharan African countries have very low education index. Many children of school age are out of school. They are either serving as domestic servants or helping their parents in their businesses. This has created a lot of problems in the social life of the people. These set of people can not explain or even know the rational behind whatever they belief in. Learning is a part of human condition and is a familiar process to everybody. It involves not only knowledge and skills, but also attitudes and social behaviour. It also implies a different internal state which may result in new behaviour and actions or new understanding and knowledge. Learning means change, but change of a relatively of permanent kind. Education enables individual worker to demand for what is his right in the organization. The level of educational development in a country influences their choices and preferences either in favour or against monetary or non-monetary motivation strategy.

\section{Government and Legal Situation:-}

The activities of organizations and individuals are guided and controlled by the laws of particular environment of their operation. Issues that relate to human behaviour and interactions in the organization are directed by laws. Most countries have labour laws governing relationship between the organization and the worker. Every country has laws that stipulate the dos and don'ts within its jurisdiction. These laws deal with a whole lot of issues ranging from remuneration and other incentives in both emerging economies and developed ones. For example in 2005 Nigeria government brought a policy known as monetization policy. This policy stipulates that every incentive of any sort would be done in monetary form. These include housing, medical, transportation etc. This policy led to sell off of all workers quarters belonging to the government. This policy of the government leaves the worker with no choice but to abide by it. It is beyond individual perception, cultural disparities within the same country. Aside this there is the issue of minimum wage policy that is general for ever government worker (Kottler and Amstrong,2010:117).

\section{Corruption in the System:-}

Corruption has been mentioned severally as the major clog in the wheel of development in most emerging economies of Sub- Saharan Africa. The former British Prime Minister, David Camelon, in 2016 in one of the United Nations Forum on African Development stated that one of the countries in African is fantastically corrupt. He made this assertion based on the amount of money government officials siphoned from the coffers of the state and transferred same to banks in the developed economies for safe keeping. These set of government official kept on loading payroll of government ministries and institutions with 'fictitious names (ghost' workers) - names of people who are being paid salaries but actually they do not exist in the real life. Their salaries are being paid into the bank account of the government officials who are perpetrating this fraud. Because of their interest they often make sure that every incentive of workers are monetary in nature. To satisfy their greed workers are compelled to accept monetary incentive.

\section{Instability in Organization:-}

Lack of management expertise and death of experience managers remain one of the greatest challenges plaguing organizations in Sub Saharan Africa. Managers with leading-edge management techniques assisted by skilful human resource on business development and continuous improvement are not easily available. This renders organisations vulnerably to competitive forces. Although many businesses operate in the environment, these businesses actually fail in their drove. They are not only bankrupt they fail also for mostly other reasons. Many do not have the need investment to carry them through the start up process. Others die out because they topple on a shaky basis of poor business planning at the initial stages and while others conceive of their ventures as a sideline to their real profession. They never make the emotional and practical investment needed to ensure continued success. Good management works wonders and can turn around an ailing business enterprise to a successful one. It creates an atmosphere in which people believe in their work. Without good management, things go out of control, plan fail to turn into action or worse. Different parts of an organization get going at different speeds, different times and with different objectives and goals. In such a situation workers will prefer monetary incentive. This is to ensure that they are not tied to the ailing organization. Their confidence in their organization has gone down. To most organisation members the continuous survival of their organization is doubtful. Interest that is paramount to them is to ensure that their money is their hand to be ready for uncertain tomorrow- the fear of the unknown (Ejiofor, 1981:643). 


\section{Historical Trend:-}

Most Sub Saharan African countries were colonised by European countries of Britain and France. Before colonisation work was mainly a voluntary service and most often settled with monetary and non-monetary means. In most instance workers were paid with food and other gift items. In those days able young men grouped themselves and went to each member's farmland and cultivate it one after the other. These they did without any financial involvement. Feeding was the means of payment. Work was mainly communal. It was a thing young men are very ready and willing to offer their friends and or in laws without expecting some thing back in return. The foundation for this system was trust. But with inception of colonialism work was now assessed and price set on each. Nothing was for free. However, there was no trust. Rather workers were doubtful and suspicious of their masters. That was because their new masters were people from foreign land. Their culture was even strange to the people. Only but very few of the workers could even understand the language of the foreigners. The colonialists showed little or no interest in the welfare of workers. Their interest is only on productivity and financial reward was the major means of remuneration. This pattern or method was carried from colonial regime and continued prevail in this modern time (Obidike,2010:76).

\section{Non-Monetary Motivation Srategies For Performance:- Setting Proper Organisation Structure:-}

Using structure as a strategy allows for free flow of work among organizational members. It also reflects objectives and plans. The structure of organization creates positions and lines of authorities which result in managerssubordinates relationship. Structure is the formal system of task, and relationship; that controls, coordinates and motivates employees to work together to achieve. It is the first strategy for motivation because it coordinates the efforts of various units and department into a common goal. It gives employees the opportunity to make their contribution towards realization of organization's objectives. Structure allows for sharing of work and exchange of knowledge and ideas among organizations' participants. The structure of organizations either promotes or inhibits healthy relationship in organization which motivates or demoralises employees. Employees share information and assist one another. They see one another as partners in progress knowing full well that combination of their efforts are required for the success of their organization. Establishing and maintaining good organizations structure motivates employees towards improving performance because it gives them platform to express themselves freely without hindrance. Structure is like the foundation and once it is not properly aligned it becomes weak and may well collapse, and requires extensive repair and support efforts in the course of time (Imaga and Ewurum, 1998:242).

\section{Making Career Progression Possible:-}

Career progression is a motivation strategy that includes promotion as at when due for employees to progress through the ranks to achieve their career their life ambition. Employees are motivated when they know they can achieve personal objectives in the organisation. Effective performance appraisal should also recognise the legitimate desire of employees' progression on their professions. One way to integrate organizational demands and individual needs is through career management. The appraisal of performance could identify the strengths and weaknesses of an individual, this identification can be the starting point of career plan. The personal strategy should be designed to utilize strengths and overcome weaknesses in order to take advantage of career opportunities. Therefore career progression can be described as a process of developing personal strategy that is conceptually similar to an organization strategy. Aligning personal objectives and organizational objectives motivates because that shows that hope of fulfilling the reasons for joining a particular organization.

\section{Manager's Friendly Disposition:-}

Friendly disposition strategy involves managers having polite, kind, respectful and caring behaviour towards employees (Templer, 2005:51). The attitude and character disposition of management or manager motivates or demoralises employees. A manager who is ever willing to listen to employee seems to show concern for their problems. One of the best ways to entertain some people is to listen to them. It motivates employees in the case of organizations. It is advisable for managers to show more affection than they felt. Employees are ready to put in their best to improve organisations performance, if management shows friendly attitude towards them. A good word is invaluable. And if management can make that their trust, they must show employees that they are doing exactly that. Trust, not only has to be done but it also has to be seen to be done. Showing employees that management believes in them, motivates. Management must show a friendly disposition that encourages one on one interaction. Once there is improvement in the relationship between management and employees, the performance is improved because employees work to impress management. 


\section{Creating Conducive Working Environment:}

One of the most desired intentions of managers is to create a work environment that motivates employees to greater productivity. Conducive environment creates opportunities for employees to express their potentials. Creating good atmosphere isn't only easy but also essential. If the employees are sullen and despondent and surly it will surely show in their performance. When employees are not happy with their work environment, their work, customers and colleagues and even their relationship with one another is affected in a negative way. Creating conducive working environment is the responsibility of management. This is because it flows from top to bottom. It may also involve apart from the attitude of management, to provision of all equipments and materials needed for employees to work optimally. Management and employees achieve objectives with the resource available. It is the availability of resources and relationship among organizational members to motivate employees to higher performance. Managers must be conscious of these two factors in order to achieve objectives. Conducive working environment makes working environment interesting and stimulates organization members to be at their work place on time with zeal and enthusiasm.

\section{Letting People Know what is expected of them:-}

The strategy of involving workers in decision making allows workers to know what and what is expected of them in a work environment. This means that organizational members are aware of the vision, mission, attitudes and behaviour, and how their performance contributes to the realization of set goals. Employees work with confidence having known they are on track. They are sure of what they are doing. It motivates employees to higher performance. However, all too often people are given jobs without knowing what is expected of them, and this most often throw them into confusion. This is most commonly noticed for new employees. They are given jobs without being told how they are expected to do it. It is fair that everyone knows what is expected of them in any given situation. This involves emotional requirements, punctuality, overtime, and behaviour towards colleagues, crisis management and general organization policy (Templer, 2005:64).

\section{Recognition of Performance:-}

People are motivated when they feel that their contribution or efforts to objectives are recognised. When individuals are praised for their contributions they always seem to improve on their productivity. This recognition may be in form of promotion or ordinary encourage or recognitions by words of mouth. Some people appreciate it when they are publicly recognised, while others appreciate it more when they are recognised in private. It is important for managers not holdback recognising employees who have performed. Compliments are always appreciated. Give praise when it is deserved. Managers must go out of their ways to affirm people frequently in a warm, friendly manner. This is important so that the sincerity of the praise will be clearly seen. Even a warm greeting, a fitting word of praise or recognition can give pleasure and make one employee feel good all day. Most employees are waiting for it. Do not deprive them that. Instead find this need in their lives and fulfil. And they will be motivated and work to please you and the organisation by ensuring that objectives are met (Osborne, 1998:19).

\section{Participation in Decision making Process:-}

Related to the above is allowing employees to be part of decision making in an organisation. Employees feel motivated by this privilege. When people are part of decision making they naturally tend to defend the decision and work assiduously to see that its intended objectives are realised. Employees feel the need to influence the decisions making process. Apart from being a motivational strategy, involving people in decision making process also gives the manager the opportunity to view event from a number of perspectives, not just his or her own. It also makes employees feel they are really contributing to the organisation and are important. When they receive such respect, they respond tremendously. Most will give their best to their organisation. It creates a sense of pride and acceptance on employees who will continue to work hard to retain and not lose such privilege. A basic understanding of this situation will be valuable for building a climate of honesty, openness and trust (Peeling, 2008:32).

\section{Job Security:-}

Employees are happy when they know that their jobs are secured. In other words, they are motivated when they are sure of their job. This enables them to show loyalty and trust for their organisations. Security of job involves remaintaining, earning of wages as at when due, being promoted as at when due etc. It guarantees settled mind and stabilises emotion. Employees work with settled mind by not being kept in suspense. In fact they are sure of the next minute, next tomorrow and so on over their job. On the bases of this, they can now put their best. Put their best means in a nutshell improved performance. Employees are motivated when they notice their organisation recognise their contribution by continuing to retain them. This situation is in no small measure helps employees to plan their 
own life based on the predictability of retaining their jobs. Every employee hopes to achieve some kind of personal objectives by working for an organisation. This can of course be possible if he continues to retain his job. That an employee is hoping to become the managing director, chief accountant or whatever or even hope to buy a car, a house or any other personal effect all depend on the predictability of retaining his job (Weihrich et al, 2010:330).

\section{Hours of Work:-}

Every industry has its working hours which are strictly followed. For example civil servants and organised private sectors have their time of dismissal. Any person who wishes to join them already knows about it. Therefore it affects the morale of employees when the hours of work are shortened or prolonged. Employees are motivated when their hours of work are shortened in order to increase their efficiency and effectiveness. Employees are demoralised when the hours of work are prolonged without any justifiable reason. Management must come up with hours of work that prevail in the industry. Management as a matter of strategy and policy maintain hours of work that recognise employees as a human person that must be treated with full dignity and respect. Exploitation must never be part of strategy to improve performance. Any hour of work that is meant to exploit workers results in demoralization unless such extra time is compensated. Workers and their unions are always ready to resist such exploitation and must often result to confrontation with management. Unless management decides to go along with prevailing hours of work, there may not be peace between workers and management.

\section{Training and Development:-}

Training is a means of increasing in skills and knowledge of employees. This can be achieved through organisation of outside training, on the job training, conferences, workshops, etc. Increase in skills boost the morale of employees and this also increase productivity as their performance improve. Skills make an employee work with ease and also happy with himself and the organisation. It helps employees meet their target and thereby earn promotion. Promotion mainly comes through performance. Promotions are earned. It is the skills set of employees that attract respect and recognition to them and to their organisations. Skills represent capabilities and abilities of employees to contribute to organisational objectives. Objectives are the centre of all activities in the organisation. It is yardstick upon which all efforts in the organisation are measured.

\section{Applying Sanction when Necessary:-}

Sanction is a mark of disapproval. It must be applied when it's necessary. Sanction may be in form of correction, suspension, disciplinary steps, denial of promotion, demotion, outright dismissal and so on. It must not in any way seem to be an intentional victimization, intimidation or singling out of a particular employee or section of organisation for maltreatment. Also, it must not be a way of pursuing sectional interest. Rather, in applying sanction management must be fair, firm, just and also forgiven if the need be. Every member of organisation must be given equal treatment and opportunity to fair hearing before facing consequences of his or her actions. This is dependent on the organisations ability to let employees know all about the policy and culture of their organisation. Sanction when applied under these circumstances becomes a strategy for motivation in organisation for it infuses on the employees a sense of responsibility and industry. It shows that there is reward for every action and inaction which serves as deterrent for indolent employees (Dessler, 2006:537).

\section{Research Methodology:-}

This chapter gives an introduction to the methodology that was adopted and used in the study. The study is on assessing the basis for acceptance of monetary motivational strategies over non-monetary motivational strategies in the Ministry of Agriculture and Rural Development of Anambra State of Nigeria. A descriptive survey research design was used in the study and chi-square was used in the test of hypothesis. The target population of 360 staff of the ministry were selected. From the questionnaire distributed 300 were returned.

Monetary and Non-monetary Motivation Strategies in the Ministry of Agriculture and Rural Development of Anambra State of Nigeria.

Table 1:- Acceptance of Monetary or Non-Monetary Motivation Strategies.

\begin{tabular}{|c|c|c|}
\hline Effects of non-monetary motivational strategies & Frequency & Percentage (\%) \\
\hline Yes & 58 & II \\
\hline No & 242 & 89 \\
\hline Total & 300 & 100 \\
\hline
\end{tabular}


58 of respondents representing $11 \%$ state that non monetary motivation strategies has influence on employee performance of Anambra State Ministry of Agriculture and Rural Development, while 242 of respondents representing $89 \%$ maintain that monetary motivational strategies has great influence on employee performance in the organisation.

Table 2:- Descriptive statistics.

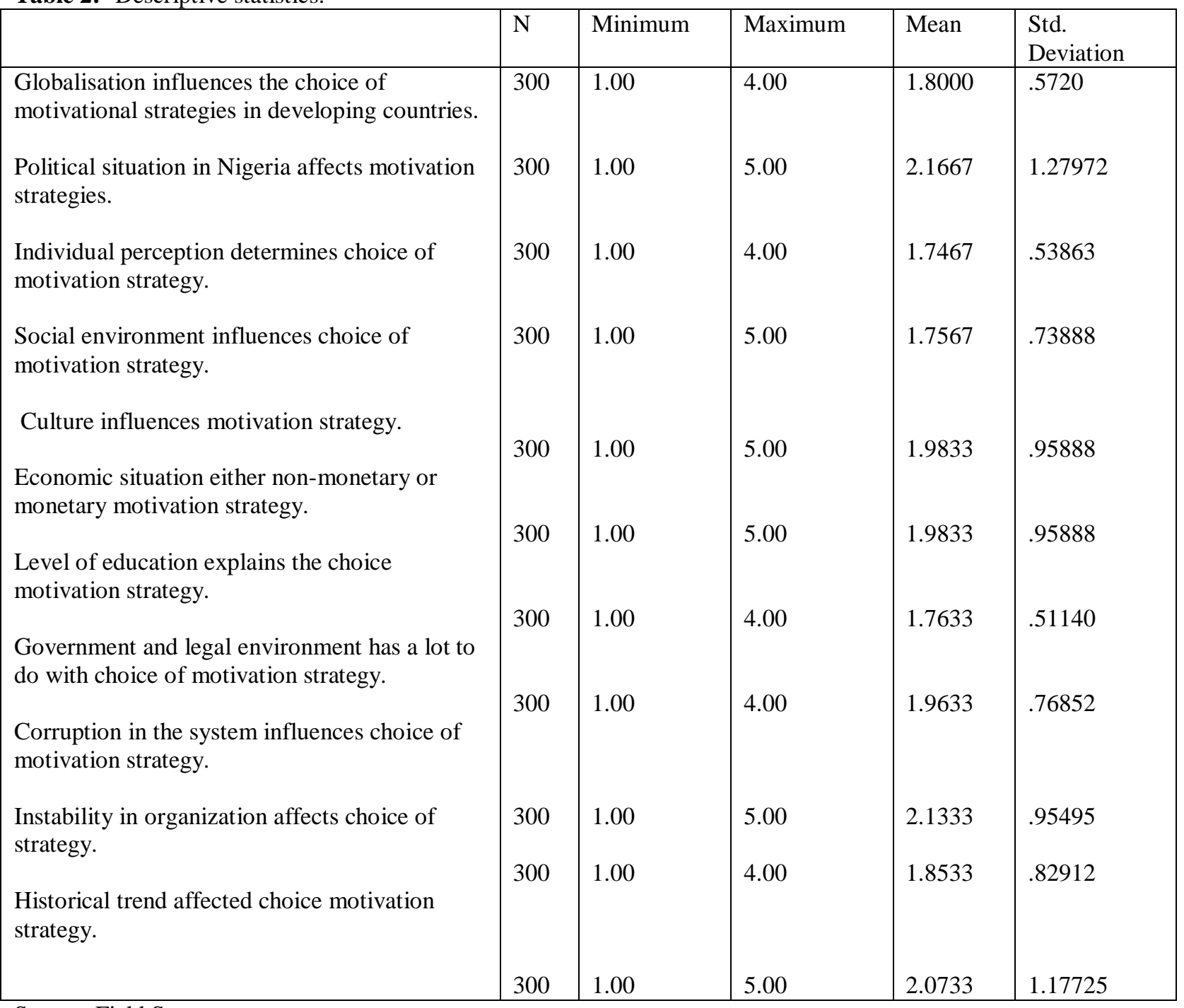

Source: Field Survey

\section{Test Of Hypothesis:-}

Hypothesis One

Ho: Monetary motivational strategy has no significant influence on employee performance.

Table 3:- Chi-square test

\begin{tabular}{|l|l|l|l|}
\hline & Value & df & Asymp Sig. $(2-$ sides $)$ \\
\hline Pearson Chi-Square likelihood & $280.229 \mathrm{a}$ & 9 & .000 \\
Ratio Linear by Linear & 268.970 & 9 & .000 \\
Association & 140.238 & 1 & .000 \\
\hline No. of valid cases & 300 & & \\
\hline
\end{tabular}

a. Cells (65.5\%) have expected count less than 5. The minimum expected count. 04 
The chi-square result shows a significant relationship between monetary incentives and employee performance in Anambra State Ministry of Agriculture and Rural Development, thus null hypothesis is accepted and alternate hypothesis rejected.

\section{Conclusion:-}

Workers accept monetary motivation than non-monetary motivation in Nigeria.

Instability in organisation promotes the choice of monetary motivation strategy.

Political instability explains the choice of monetary motivation strategy.

Poor economic situation in the country favours the acceptance monetary motivation over non- monetary strategies.

Corruption in the system favours monetary motivation strategy.

Education enables workers to make informed choice between monetary and non-monetary motivation strategy.

\section{Recommendations:-}

1. Non-monetary motivation strategies should be explored in Nigeria as a means of creating alternative motivation for workers.

2. Training and development should be made compulsory for managers of institutions.

3. Workers should be given the opportunity to make a choice.

4. Managers should abstain from any act that would deem to be exploitative or intimidation of subordinates.

5. Individual, cultural, social, economic, political etc, differences should be considered in setting motivation strategies.

6. Strategy to curb corruption in Nigeria should be strengthened.

\section{References:-}

1. Akpala, A. (1991), Management: An Introduction and the Nigerian Perspective, Enugu, Sunshine Press.

2. Belasco, J.A. et al, (1981), Management Today, New York, John Wiley and Sons.

3. Brown, S. (1999), Fatal Errors Managers Make, Benin, Beulahland Publishing Ministry.

4. Dessler, G. (2005), Human Resource Management, New Jersey, Pearson.

5. Dess, G. (2009), Strategic Management: Text and Cases, New York, McGrawHill.

6. Drucker, P. (1977), Management: Responsibility, Task, New York, Heineman.

7. Ejiofor, P. (1981). Management in Nigeria: Theories and Issues. Onitsha, Education Publishers Nigeria.

8. Ejiofor, P. and Aniagoh, V. (1984), Managing the Nigerian Worker, Lagos, Longman Publishers.

9. Haimann, T. and Scott, W. (1970), Management in Modern Organisation, New York, Houghton Mifflin Co.

10. Imaga, EUL and Ewurum, UJF (1998), Business Management Topics, Enugu, Oktek Publishers.

11. Kothari, C. (2014), Research Methodology: Concept and Cases, New Delhi, New Age Publishers.

12. Kottler, P. and Amstrong P. (2010), Principles of Marketing, London, Pearson Publishers.

13. Kottler, P. and Keller (2007), Marketing Management, London, Pearson Publisher.

14. Kumar, R. and Nadhi (2013), International Business Text and Cases, New Delhi, UDH.

15. Newstrom, J. (2015), Organisational Behaviour, New York, McGrawHill.

16. Osborne, C. (1998), The Art of Getting Along with People, Michigan, Zondervan Publishing House.

17. Peeling, N. (2008), Brilliant Manger, Great Britain. Pearson.

18. Sutermeister, R. (1963), People and Productivity, New York, McGraw.

19. Templar, R. (2005), Rule of Management, Great Britain, Pearson Education.

20. Thompson, A. and Strickland, A. (2010), Strategic Management: Concepts and Cases, New York, McGrawHill.

21. Weihrich, H. et al (2010), Management: A Global and Entrepreneurial Perspective, New York, McGraw Hill.

22. Wheleen, G. and Hunger, J.D. (2009), Strategic Management and Business Policy, London, Pearson.

23. Wild, J. And Wild, k. (2013), International Business: The Challenges of Globalisation, London, Pearson.

24. Wheleen, G. And Hunger, J. (2009), Strategic Management and Business Policy, London, Paerson Publishers. 